Jens Juel (1745-1802)

\title{
Ein Maler des 18. Jahrhunderts
}

\author{
Schon früh entdeckte Jens Juel, Sohn eines Schulmeisters, sein \\ Interesse für die Kunst des Malens. Sein Talent und Ehrgeiz machten \\ den Dänen zu einem bedeutenden Maler des skandinavischen Rokoko. \\ Zu seinen Schülern zählte auch Caspar David Friedrich.
}

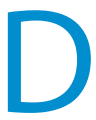
as Gemälde des kleinen späteren Prinzen von Noer kann man im Kunstmuseum in Kiel bewundern. Sein hierzulande wenig bekannter dänischer Maler Jens Joergensen Juel lebte nicht weit davon in Kopenhagen. Es ziert den schönen Katalog der Ausstellung „KINDERZEIT, Kindheit von der Renaissance bis zur Moderne", die 2013 im Museum Oldenburg stattfand.

Es ist kein Mädchen - wie man zunächst vermuten könnte - das uns oder wahrscheinlich seiner Mutter die rechte Hand entgegenstreckt. Es handelt sich vielmehr um einen Jungen, zu dem auch das Spielzeug, die Trommel, die Reitgerte und das Ziehpferdchen passen. Sie weisen auf dessen Bestimmung als Feldherr hin. Und so soll der Prinz von Noer im ersten Deutsch-Dänischen Krieg

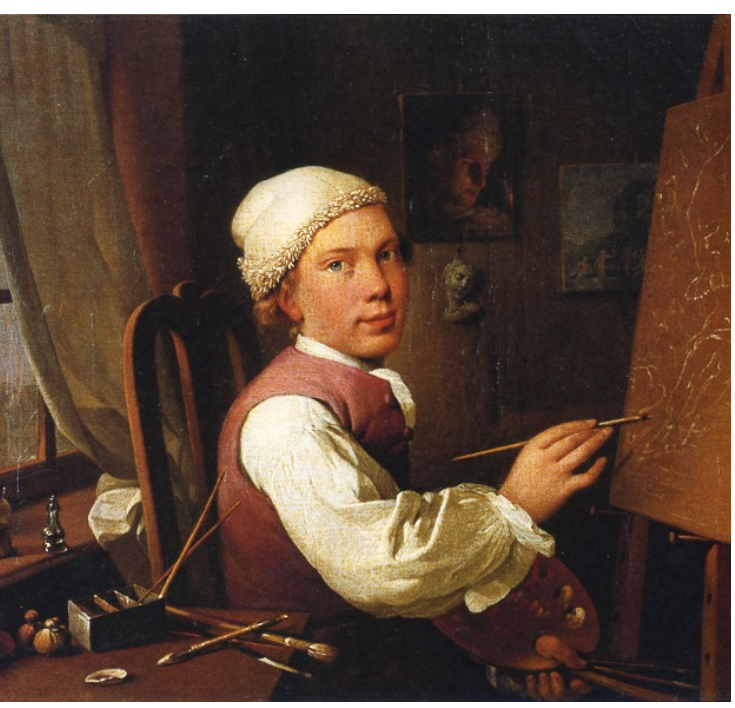

Jens Juel "Selbstbildnis an der Staffelei“ (1766)
(1848-1852) die schleswig-holsteinischen Truppen angeführt haben. Später sei er Befehlshaber der Kavallerie geworden. Der im Alter von zwei Jahren hier porträtierte Friedrich Emil August trägt einen Hemdenkittel, wie ihn sowohl wohlhabende Mädchen als auch Jungen im 18. Jahrhundert trugen. Und offensichtlich schon damals verlangten kleine Kinder nach der Mutter, wenn sie des Spielens müde waren, um auf den Arm gehoben zu werden.

\section{Kinder in der Kunst}

Die Kunst kennt das spielende Kind seit der Antike. Die wohl schönsten Bilder kindlichen Spielens haben die niederländischen Genremaler des 17. Jahrhunderts gemalt. Etwa ab Mitte des 18. Jahrhunderts veränderte die Gesellschaft ihre Sicht auf das Kind. Jean-Jacques Rousseau (1712-1778) schrieb 1762 den Erziehungsroman „Émile oder über die Erziehung“. Die „Kindheit“ wurde erfunden und als Neubeginn und vollwertige Lebensspanne verstanden. In den Gemälden tauchen kindliche Attribute wie Bilderbücher und Spielzeug symbolisch auf. Lange Zeit wurden Kinder mit geschlechtsspezifischen Spielzeug abgebildet: Mädchen mit Puppen und Puppenherd, Jungen mit Bauklötzen und teilweise mit Kriegsspielzeug. Das Kinderleben wurde in Genrebildern über das Alltagsleben der bürgerlichen $\mathrm{Ge}$ sellschaft in Szene gesetzt.

\section{Der Weg zum Akademiedirektor}

Der Maler Jens Juel zählt zu den bekanntesten und bedeutendsten Porträtmalern Dänemarks. Er wurde am 12. Mai 1745 in Balslev auf der Insel Fünen geboren,

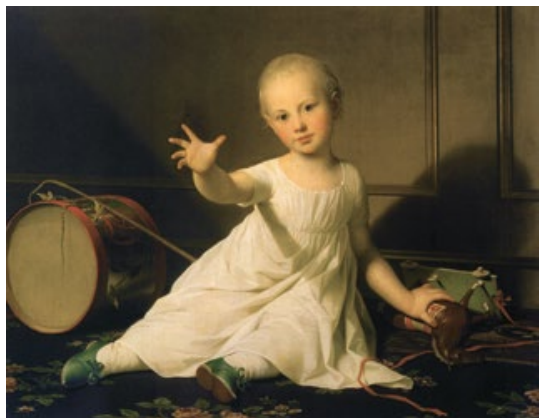

Jens Juel „Herzog Friedrich Emil August von Schleswig-Holstein-Sonderborg-Augustenburg, gen. Prinz von Noer" (1802)

erhielt eine Lehre in Hamburg und kehrte 1766 nach Dänemark zurück. Nach Aufenthalten in Hamburg, Dresden, Rom, Paris und der Schweiz unterrichtete er ab 1786 als Kunstlehrer. Gleichzeitig wurde er zu einem gefragten Bildnismaler und zum königlichen Porträtmaler (Hofmaler) ernannt. Aber auch seine Landschaftsbilder begründeten seinen guten Ruf. Als Kunstprofessor war Juel von 1795-1797 sowie von 17991801 Direktor der Kunstakademie in Kopenhagen. Seine erfolgreichsten deutschen Schüler wurden Caspar David Friedrich (1774-1840) und Philipp Otto Runge (1777-1810).

Im 18. und 19. Jahrhundert war die „Kongelige Danske Skildre-, Bildhuggerog Bygnings-Academie“ ein geistig-kulturelles Zentrum mit starker Wirkung auf die europäische Kunst. Dabei soll sie die liberalste Akademie Europas gewesen sein. Zahlreiche deutsche Künstler ließen sich dort ausbilden. Und vor allem entwickelte die „Kopenhagener Schule“ eine eigenständige dänische Kunst, die in den letzten Jahren in Deutschland mit großen Ausstellungen vorgestellt und gewürdigt wurde. Jens Juel gehört zu seinen wichtigsten Vertretern und Wegbereitern. Er verstarb am 27. Dezember 1802 in Kopenhagen.

Dr. Joachim Gunkel 